\title{
Biomarkers for Lupus Nephritis: A Critical Appraisal
}

\author{
Chi Chiu Mok \\ Department of Medicine \& Geriatrics, Tuen Mun Hospital and Center for Assessment and Treatment of Rheumatic Diseases, \\ Pok Oi Hospital, Hong Kong
}

Correspondence should be addressed to Chi Chiu Mok, ccmok2005@yahoo.com

Received 5 January 2010; Accepted 22 March 2010

Academic Editor: Charles Via

Copyright ( 92010 Chi Chiu Mok. This is an open access article distributed under the Creative Commons Attribution License, which permits unrestricted use, distribution, and reproduction in any medium, provided the original work is properly cited.

\begin{abstract}
Kidney disease is one of the most serious manifestations of systemic lupus erythematosus (SLE). Despite the improvement in the medical care of SLE in the past two decades, the prognosis of lupus nephritis remains unsatisfactory. Besides exploring more effective but less toxic treatment modalities that will further improve the remission rate, early detection and treatment of renal activity may spare patients from intensive immunosuppressive therapies and reduce renal damage. Conventional clinical parameters such as creatinine clearance, proteinuria, urine sediments, anti-dsDNA, and complement levels are not sensitive or specific enough for detecting ongoing disease activity in the lupus kidneys and early relapse of nephritis. Thus, novel biomarkers are necessary to enhance the diagnostic accuracy and sensitivity of lupus renal disease, prognostic stratification, monitoring of treatment response, and detection of early renal flares. This paper reviews promising biomarkers that have recently been evaluated in longitudinal studies of lupus nephritis.
\end{abstract}

\section{Introduction}

Glomerulonephritis is one of the commonest and most serious manifestations of systemic lupus erythematosus (SLE) $[1,2]$. Renal involvement in SLE carries significant morbidity and mortality. The 5- and 10-year renal survival rates of lupus nephritis in the 1990s range between $83 \%$ $92 \%$ and $74-84 \%$, respectively [3]. The prognosis of lupus nephritis is particularly bad in certain ethnic groups such as the Africans and Hispanics [4].

Despite the overall improvement in the care of SLE in the past two decades, the prognosis of lupus nephritis remains unsatisfactory. Up to $25 \%$ of patients still develop end stage renal failure 10 years after onset of renal disease [5]. In order to improve the prognosis of lupus nephritis further, newer strategies with better efficacy but lower toxicities are necessary. This can be achieved by modification of existing regimens, combination strategies, or more specific targeting at the immunopathogenetic pathways by novel biological agents such as rituximab, belimumab, abatacept, and abetimus [6]. However, to the disappointment of the lupus community, data from recent clinical trials on targeted therapies of SLE are discouraging. While the clinical and immunological heterogeneity of SLE and flaws in study design and outcome measures may contribute to the futility of these trials, more sensitive and specific clinical markers for the onset or relapse of renal disease activity in patients with SLE may allow earlier institution of treatment and even preventive strategies so that the efficacy of existing therapies can be enhanced while treatment-related complications can be minimized. In addition to the refinement of outcome assessment tools in SLE, inclusion of novel biomarkers as surrogate end-points in future lupus nephritis clinical trials may increase the feasibility of identification of subsets of patients who would benefit most from the newer regimens.

\section{Unmet Needs for Novel Biomarkers in Lupus Nephritis}

Current laboratory markers for lupus nephritis such as proteinuria, urine protein-to-creatinine ratio, creatinine clearance, anti-dsDNA, and complement levels are unsatisfactory. They lack sensitivity and specificity for differentiating renal activity and damage in lupus nephritis. Significant kidney damage can occur before renal function is impaired and first detection by laboratory parameters. Persistent proteinuria may not necessarily indicate ongoing inflammation in the 
kidneys and may be contributed by pre-existing chronic lesions or recent damage in the kidneys during the course of the disease. Flares of nephritis can occur without any observable and recent increase in the degree of proteinuria. Renal biopsy is the gold standard for providing information on the histological classes of lupus nephritis and the relative degree of activity and chronicity in the glomeruli. However, it is invasive and serial biopsies that are impractical in the monitoring of lupus nephritis. Thus, novel biomarkers that are able to discriminate lupus renal activity and its severity, predict renal flares, and monitor treatment response and disease progress are clearly necessary.

A biomarker refers to a biologic, biochemical, or molecular event that can be assayed qualitatively and quantitatively by laboratory techniques. The levels of biomarkers should correlate with disease pathogenesis or activity in different organ systems. An ideal biomarker for lupus nephritis should possess the following properties: (1) good correlation with renal activity as reflected by the degree of proteinuria and urine sediments, (2) sensitive to change so that it can be used for serial monitoring of disease activity in the kidneys and defining treatment response and clinical remission, (3) ability to predict renal activity/flares before an obvious change in conventional clinical parameters occurs so that early treatment/preventive strategies can be considered, (4) specific to nephritis among patients with SLE, and (5) specific to SLE for aiding early diagnosis of lupus nephritis. In addition, a useful biomarker should be easy to assay, simple to interpret, and readily available in most laboratories with a reasonable cost.

Hitherto, quite a number of serum and urine biomarkers have been studied in lupus nephritis. Most of these markers have only been tested in cross-sectional studies and only a few have been evaluated in longitudinal studies. The number of patients having been tested is relatively small and the results have not been confirmed by independent groups of investigators. Even for biomarkers that have been prospectively evaluated, further validation has to be performed in larger groups of patients with lupus nephritis.

In this paper, biomarkers that have been recently studied in lupus nephritis are systematically reviewed. Information is grouped under three subheadings: (1) biomarkers that correlate with SLE renal activity in longitudinal studies, (2) biomarkers that correlate with lupus nephritis activity in cross-sectional studies, and (3) biomarkers that correlate with renal histology or prognosis of lupus nephritis.

\section{Biomarkers That Correlate with Lupus Renal Activity in Longitudinal Studies}

3.1. Chemokines. Monocyte chemoattractant protein1 (MCP-1) is a leukocyte chemotactic factor that is involved in mediating inflammation and injury in lupus nephritis [7]. In murine models of lupus nephritis, genetic depletion or blockade of MCP-1 ameliorates glomerular and interstitial inflammation and hence renal damage $[8,9]$. In human lupus nephritis, increased expression of MCP-1 on endothelial cells, renal epithelial cells, and infiltrating mononuclear cells in the tubulointerstitial regions can be demonstrated by immunohistochemical staining and in situ hybridization [10].

Level of MCP-1 in urine is increased in patients with a variety of glomerulonephritis and correlates with the extent of proteinuria and the severity of glomerular lesions [11] . In patients with SLE, urine MCP-1 levels are elevated in those with active nephritis and reduced after immunosuppressive treatment $[10,12]$. A number of recent cross-sectional studies have confirmed that levels of urine MCP-1 are elevated in patients with active lupus nephritis compared to those with inactive renal disease or healthy controls [13-15].

Rovin et al. [14] studied a cohort of adult SLE and measured urinary MCP-1 (uMCP-1) levels at the time of lupus flares and when available, before and after these flares. The mean uMCP-1 level at the time of renal flares was significantly higher than that of healthy controls, patients with inactive renal disease and patients with active or inactive nonrenal SLE. As uMCP-1 level did not correlate with nonrenal SLE activity, it was likely to be specific for renal activity. In addition, uMCP-1 was also found to be a sensitive indicator for renal flare, with $73 \%$ of the flare values above the 95th percentile of disease controls. uMCP-1 levels were higher in patients with proliferative (WHO class III or IV) than membranous (class V) nephritis. There was no relationship between the cumulative amount of immunosuppressive therapies received within 30 days preceding a renal flare and uMCP-1 levels. In longitudinal follow-up of 12 patients, uMCP- 1 increased as early as 2 to 4 months before renal flares. uMCP-1 levels remained high for at least 4 months after treatment of flares. In patients who improved clinically, uMCP-1 levels fell to control levels, whereas in patients who were refractory to treatment, uMCP1 remained high. Some patients had persistently elevated uMCP-1 despite improvement in proteinuria, suggesting the possibility of ongoing subclinical inflammation in the kidneys.

Similar findings of uMCP-1 in lupus nephritis were reported by Tian et al. [16]. In this study, 73 patients with diffuse proliferative lupus nephritis were followed. After an observation of 2 years, 22 patients experienced renal flares. Patients experiencing renal flares showed higher levels of MCP-1 in their urine samples. Using a different approach, Chan et al. [17] prospectively examined the expression of chemokine mRNAs in urinary sediments of 9 patients with active lupus nephritis for 24 weeks. The major component of urinary sediments is renal tubular epithelial cells and leukocytes (predominantly $\mathrm{T}$ cells) that make up only a quarter of the sediments. It was demonstrated that urinary mRNA expression of MCP-1 and other chemokines correlated significantly with SLE disease activity scores and anti-dsDNA titers during the course of immunosuppressive treatment.

Overall, uMCP-1 is a promising biomarker for lupus nephritis. It is specific for renal activity, sensitive to predict renal flares and correlates with severity of flares and proliferative types of lupus nephritis. However, further longitudinal validation of uMCP-1 in larger cohorts of patients with lupus nephritis is necessary. 
3.2. Neutrophil Gelatinase-Associated Lipocalin (NGAL). Lipocalin-2 is a small glycosylated protein produced in many tissues and organs. Lipocalin-2 was first described in human neutrophil granules as neutrophil gelatinaseassociated lipocalin (NGAL). NGAL belongs to a family of carrier proteins that are important for cellular iron transport, apoptosis, bacteriostasis, and tissue differentiation. NGAL is constitutively expressed at low levels in the kidneys [18] but upregulated following acute renal injury and various insults such as inflammation, ischemia, and infection [1922]. An early rise in urinary and plasma NGAL levels after cardiopulmonary bypass surgery in children is predictive of acute kidney injury with high sensitivity and specificity [23]. In addition, serum and urine NGAL levels correlate with residual glomerular filtration rate better than serum creatinine and are good biomarkers for chronic kidney disease $[24,25]$. A recent work has shown that NGAL expression was dramatically upregulated in kidney mesangial cells derived from lupus-prone mice after in vitro treatment with the murine nephritogenic anti-dsDNA monoclonal antibodies [26].

Two cross-sectional studies have examined the relationship between NGAL levels and human lupus nephritis [27, 28]. Brunner et al. [27] reported higher levels of urine NGAL levels (adjusted for urinary creatinine) in pediatric patients with SLE compared to juvenile idiopathic arthritis. Subgroup analysis showed that the difference of urine NGAL (uNGAL) levels was only significant between patients with biopsy-proven lupus nephritis and idiopathic arthritis. uNGAL levels correlated with urine protein-to-creatinine ratios and were associated with renal SLE disease activity scores only, but not with global damage or extrarenal disease activity scores. Among SLE patients, a higher uNGAL level could differentiate between those with and without active renal disease. UNGAL was found to correlate more strongly with histologic activity scores than chronicity scores on renal biopsies. Pitashny et al. [28] studied 70 adult SLE patients (of whom 32 had active renal disease) and similarly demonstrated that urinary NGAL levels were significantly higher in lupus nephritis than in nonrenal SLE patients or healthy controls. Urine NGAL levels correlated with renal but not with extrarenal SLE disease activity scores. Among patients with lupus nephritis, urine NGAL levels correlated significantly with urine protein-to-creatinine ratios but not with proteinuria, serum creatinine level, or conventional lupus markers such as anti-dsDNA and complement levels.

Longitudinal data on NGAL in lupus nephritis are recently available. Suzuki et al. [29] studied 85 pediatric SLE patients and reported that both plasma and urine NGAL levels were significantly higher in patients with SLE than juvenile idiopathic arthritis or healthy controls and were unrelated to age, body weight, and height. Urine but not plasma NGAL levels correlated with renal disease activity scores. In patients with renal biopsy performed, uNGAL levels were higher in diffuse proliferative than membranous lupus nephritis. Patients with worsening global or renal disease activity had increased levels of uNGAL and NGAL/creatinine. Increase in serum NGAL levels occurred at a much less degree and was not statistically significant.
The authors postulated that the sources of uNGAL in lupus nephritis could be injured renal tubular cells, neutrophils, or inflamed vasculature. They also emphasized that elevation of uNGAL might be a reflection of renal injury/inflammation, which was not specific to lupus renal disease.

Another longitudinal study on NGAL was carried out in 111 pediatric SLE patients [30]. SLE disease activity using three standard disease activity indices and levels of plasma and urinary NGAL were assessed quarterly. It was demonstrated that a significant increase in uNGAL/creatinine levels of up to $104 \%$ was detected up to 3 months before worsening of lupus nephritis as measured by all the three disease activity indices. Plasma NGAL level also increased significantly by $26 \%$ as early as 3 months before worsening of global SLE disease activity (by all three disease indices) and renal activity as measured by the BILAG renal score. Although the extent of change in levels is much greater with urine compared to plasma NGAL in this study, both biomarkers have a value in predicting worsening of renal disease activity in childhood lupus nephritis.

Finally, a more recent longitudinal study confirmed that urine NGAL level was a significant predictor of renal disease activity in SLE patients and a significant predictor for flares in patients with a history of biopsy-proven nephritis [31]. The specificity and sensitivity of urine NGAL level in predicting renal flares was higher than that of anti-dsDNA titer.

3.3. Tumor Necrosis Factor-Like Inducer of Apoptosis (TWEAK). Tumor necrosis factor- (TNF-) like inducer of apoptosis (TWEAK) is a multifunctional cytokine that belongs to the TNF-ligand superfamily. The main source of soluble TWEAK is believed to be the macrophages. TWEAK binds to its cognate receptor, Fn14, in various tissues and mediates a number of physiological processes such as cellular proliferation, survival, differentiation, migration, and angiogenesis [32]. TWEAK/Fn14 interaction has also been found to be involved in upregulation of proinflammatory mediators and induction of cell death and apoptosis (weak effect) [18]. While TWEAK expression is low in normal tissues, it is dramatically increased in the context of inflammation and injury. Thus, it is thought that TWEAK is important in the physiological processes of tissue repair and regeneration but its expression is dysregulated in chronic inflammatory states [33].

It is recently shown that ex vivo stimulation of murine and human kidney cells by TWEAK induces the expression of chemokines and inflammatory mediators such as MCP-1, RANTES, IFN-gamma-induced protein 10 (IP-10), ICAM-1, and VCAM-1 $[34,35]$, which are relevant to the induction of inflammation through cellular recruitment and progression of lupus nephritis. Another postulated pathogenetic mechanism of SLE is impaired clearance of apoptotic materials by macrophages [36]. Increased expression of TWEAK on activated lupus $\mathrm{T}$ cells has been shown to induce monocyte/macrophage apoptosis, which may contribute to the initiation of SLE through increasing the burden of apoptotic materials [37]. 
A pilot cross-sectional study demonstrated that urinary TWEAK (uTWEAK) levels were significantly higher in SLE patients with active nephritis as compared to those with inactive or no nephritis [38]. Moreover, uTWEAK levels correlated with the renal SLE disease activity scores, serum anti-dsDNA, and complement levels, as well as urine MCP-1 levels. However, uTWEAK did not correlate with proteinuria, suggesting that its increased level was not due to nonspecific release as a result of glomerular damage.

A further multicenter longitudinal study involving 30 biopsy-proven lupus nephritis patients and five control groups (normal, nonrenal SLE, rheumatoid arthritis, osteoarthritis and, non-SLE renal diseases) showed that uTWEAK levels were significantly higher in patients with lupus nephritis than nonrenal SLE, rheumatoid arthritis, and healthy controls [39]. As the uTWEAK levels in nonrenal SLE patients were not significantly different from those of the control groups, elevation of uTWEAK was unlikely a feature of nonrenal lupus. However, there was some overlap of the uTWEAK values of lupus nephritis patients with controls, indicating that uTWEAK was not totally specific for lupus renal disease. In a logistic regression model, it was demonstrated that high uTWEAK levels (adjusted for urinary creatinine) were independently associated with renal involvement among patients with SLE, after adjustment for age, sex, and ethnicity. UTWEAK was superior to anti-dsDNA or complement levels in differentiating lupus nephritis from nonrenal SLE patients. Although uTWEAK levels correlated with renal SLE disease activity scores, there was no significant association between uTWEAK levels and histological classes of lupus nephritis.

Thirteen patients with flares of lupus nephritis were longitudinally evaluated. The UTWEAK levels peaked at the time of flares, with an increasing trend before the flares and a decreasing trend after the flare events. The uTWEAK levels were significantly higher during renal flares than those values 4-6 months before and after the flares. A significant association between uTWEAK levels in SLE patients and their renal disease activity scores over time was also found. However, the small increase in the levels of uTWEAK 2 months before renal flares from baseline was not statistically significant.

Overall, although uTWEAK is a promising biomarker for lupus nephritis because of its high specificity for lupus renal disease and good correlation with renal disease activity, it may not be sensitive enough to predict a renal flare early and cannot replace the need for a renal biopsy.

3.4. Urine Proteomics. Suzuki et al. [40] utilitized the surfaceenhanced laser desorption/ionization time-of-flight mass spectrometry (SELDI-TOF MS) technology to isolate a panel of urinary protein signature for pediatric patients with lupus nephritis. Eight candidate peptides/proteins of molecular mass from 2.7 to $133 \mathrm{kD}$ were identified. Four of these were albumin or albumin fractional products and the others were transferrin (TF), $\alpha 1$-acid-glycoprotein (AGP), ceruloplasmin (CP), and lipocalin-type prostaglandin D-synthetase (LPGDS). In a preliminary study of 32 SLE patients, the peak intensities of these biomarkers were significantly greater in patients with nephritis compared with controls and those without nephritis [40]. The biomarkers strongly correlated with renal disease activity and moderately with renal damage.

Using a similar technique, Mosley et al. [41] identified a panel of urine proteins and examined whether they were able to differentiate between patients with active and inactive lupus nephritis. In their study, it was found that proteins with masses of 3340 and 3980 best distinguished active from inactive renal disease in SLE. Multiple regression scores calculated from a linear equation derived from the discriminant analysis of these proteins were shown to predict renal flares and remission earlier than traditional clinical markers in 6 patients with renal biopsy-confirmed lupus nephritis and serial urine samples tested.

In a further validation study, Suzuki et al. [42] measured serially the urinary concentration of TF, AGP, CP, and LPGDS using immunonephelometry or ELISA in 98 children with SLE and 30 controls with juvenile idiopathic arthritis. All these urinary signature proteins were significantly higher in patients with active than inactive or no lupus nephritis, as well as arthritis controls. By analyzing the area under the receiver operating characteristic (ROC) curves, it was shown that these urinary signature proteins performed better than traditional renal markers such as complement levels, creatinine clearance, and urine protein-to-creatinine ratio in differentiating the presence of active lupus nephritis as measured by the renal SLEDAI and BILAG scores. Prospective data revealed significant increases of urinary TF, L-PGDS, and AGP occurred as early as 3 months before a clinical diagnosis of worsening lupus nephritis. The result appeared to be most promising for transferrin because its level increased exclusively in those patients with worsening nephritis but not in those with improved nephritis, stable active or inactive nephritis, suggesting that it was a more sensitive biomarker for a change in renal disease activity than L-PGDS and AGP. There was no relationship between urinary ceruloplasmin level and renal flares. The predictive value of a combination of these panel signature proteins for renal flares was not assessed in this study.

Hepcidin is a low-molecular-weight peptide hormone mainly produced by the liver. Hepcidin has antimicrobial activity, regulates iron metabolism, and is thought to be involved in the pathogenesis of anemia of chronic illness including chronic kidney disease [43]. Urinary excretion of hepcidin is greatly enhanced in patients with iron overload, infections, or inflammatory diseases [44]. Hepcidin is also an acute phase reactant and is upregulated by interleukin- 6 and interleukin-1 [45], which are cytokines implicated in the pathogenesis of SLE. Using SELDI-TOF mass spectrometry, Zhang et al. [46] identified the 20 and 25 amino acid isoforms of hepcidin as potential urine biomarkers for lupus nephritis. In a prospective study of 25 flare cycles in 19 patients with biopsy-proven lupus nephritis [46], it was shown that urine hepcidin-20 concentration increased significantly 4 months before renal flares and returned to baseline within 4 months. Urine hepcidin-25, however, showed a reverse pattern of expression, with concentration decreased during renal flares and returned to baseline 4 months after the flare events. 
Taken together, serial urine proteomic analysis is potentially useful in the early detection of flares in lupus nephritis and the monitoring of treatment response. However, further validation studies are necessary.

\subsection{Autoantibodies}

3.5.1. Anti-C1q Antibodies. C1q is the first component of the classical pathway of the complement system. C1q plays a crucial role in the clearance of immune complexes and apoptotic bodies [47]. Prolonged exposure to C1q epitopes to the immune system may induce autoimmune phenomena. Both humans and mice with C1q deficiency are at risk of developing lupus-like syndromes and immunemediated glomerulonephritis because of defective clearance of apoptotic cells, autoantigens, and immune complexes [48]. Anti-C1q autoantibodies were first found in the sera of patients with SLE although subsequently they could have also been demonstrated in patients with hypocomplementemic urticarial vasculitis, rheumatoid arthritis, human immunodeficiency virus infection, non-SLE active glomerulonephritis, and other organ-specific autoimmune diseases.

Anti-C1q antibodies are present in $20 \%-44 \%$ of patients with SLE in cross-sectional studies and are associated with the presence of nephritis [49-54]. Titers of anti-C1q correlate with global SLE disease activity scores [54-57]. In patients with lupus nephritis, anti-C1q titer strongly correlates with renal disease activity $[51,54,58,59]$, with a sensitivity of $44 \%-100 \%$ and a specificity of $70 \%-92 \%$ in various studies [60].

Two recent prospective studies examined the value of anti-C1q antibodies in monitoring of activity of lupus nephritis and predicting flares [61, 62]. Meyer et al. [61] followed 70 SLE patients with and without evidence of nephritis at baseline. In 15 patients who subsequently developed nephritis, anti-C1q titers were elevated in all (100\%) of them compared to only $45 \%$ in those who did not develop renal disease. The median anti-Clq titer was also significantly higher in patients with subsequent renal disease than those without. With immunosuppressive treatment, anti-C1q titers decreased but remained elevated in some lupus nephritis patients. The corresponding figures for elevation of anti-dsDNA titers in patients who did or did not subsequently develop nephritis were $93 \%$ and $73 \%$, respectively. Anti-C1q did not correlate with anti-dsDNA titer or SLE disease activity scores. Elevation of anti-C1q titer had $50 \%$ positive predictive value and $100 \%$ negative predictive value for the subsequent development of class IV or V lupus nephritis.

Moroni et al. [62] measured the anti-Clq titers in serial serum samples collected from 228 patients with lupus nephritis over 6 years. In proliferative lupus nephritis, elevation of anti-C1q level predicted renal flares with a sensitivity and specificity of $81 \%$ and $71 \%$, respectively, which was only marginally better than other individual markers such as anti-dsDNA, C3, and C4 levels. At multivariate analysis, a combination of anti-C1q, C3, and $\mathrm{C} 4$ provided the best performance for predicting renal flares. A combination of the anti-C1q, anti-dsDNA, C3, and C4 tests had a good negative predictive value, meaning that in the presence of normal values of these 4 tests, active lupus nephritis was unlikely. The sensitivity and specificity of anti-C1q elevation in predicting renal flares was much lower with the membranous type of lupus nephritis. Up to $46 \%$ of flares occurred with a normal value of anti-C1q antibodies.

Although an elevation of anti-C1q titer is shown to predict the development of lupus nephritis or renal flares in these studies, its performance is not significantly better than that of anti-dsDNA and complement levels. The high negative predictive value of anti-C1q for severe renal disease may be helpful for prognostic stratification of SLE patients. The usefulness of anti-C1q level in monitoring of lupus activity in patients with negative anti-dsDNA antibodies has to be further explored.

3.5.2. Antinucleosome Antibodies. Nucleosomes released by apoptotic cells are major $\mathrm{T}$ and $\mathrm{B}$ cell autoantigens in SLE [70]. Nucleosomes may act as bridging molecules that recognize heparin sulphate/collagen components of the glomerular basement membrane for the binding of antinucleosome and other nephritogenic antibodies [71]. A recent electron microscopic study of renal tissues from patients with lupus nephritis confirms that autoantibodies colocalize with electron-dense extracellular deposits of chromatin, suggesting that intraglomerular membrane-associated nucleosomes are targeted by nephritogenic autoantibodies [72].

A recent review summarizes 13 cross-sectional studies of antinucleosome antibodies in lupus [79]. Antinucleosome antibodies have a sensitivity ranging from 48 to $100 \%$ and a specificity ranging from $90 \%$ to $99 \%$ for SLE. Antinucleosome antibodies are associated with renal involvement in some studies $[80,81]$ and their titers correlate with SLE disease activity scores. The frequency of antinucleosome antibodies in active SLE is similar to that of anti-dsDNA antibodies, and the titers of these autoantibodies correlate with each other in most studies.

The change in antinucleosome antibodies over time in 52 patients with active proliferative lupus nephritis treated with high-dose glucocorticoids and either cyclophosphamide or azathioprine in a prospective controlled clinical trial was studied [82]. At baseline, patients with high titers of the antinucleosome antibodies had significantly higher SLE disease activity scores. A rapid decline in the levels of antinucleosome antibodies occurred after treatment but renal flares were not preceded by a rise of either the antinucleosome or anti-dsDNA antibodies.

In another more recent study, 16 patients with biopsyconfirmed lupus nephritis were prospectively evaluated for the relationship between antinucleosome titers and parameters of renal disease activity [92]. At baseline, antinucleosome titers were significantly higher in patients than controls. Over the follow-up period, levels of antinucleosome correlated with those of anti-dsDNA. Both antinucleosome and antidsDNA antibody titers were significantly associated with urine protein-to-creatinine ratio and serum albumin level. 
TABLE 1: Serum biomarkers that correlate with lupus nephritis activity in cross-sectional studies.

\begin{tabular}{|c|c|c|}
\hline Authors, year & Biomarkers studied & Main findings \\
\hline $\begin{array}{l}\text { Hoftman et al., } \\
2008[63]\end{array}$ & MAGE-B2 antibodies & $\begin{array}{l}\text { Positive melanoma-associated antigen gene B2 (MAGE-B2) antibody associated } \\
\text { with higher SLE disease activity score and active lupus nephritis }\end{array}$ \\
\hline $\begin{array}{l}\text { Tan et al., } 2008 \\
\text { [64] }\end{array}$ & Anti-CRP antibody & $\begin{array}{l}\text { IgG autoantibody against monomeric CRP prevalent in patients with lupus } \\
\text { nephritis and associated with SLE disease activity score and renal tubulointerstitial } \\
\text { lesions }\end{array}$ \\
\hline $\begin{array}{l}\text { Tucci et al., } 2008 \\
\text { [65] }\end{array}$ & Serum and urine IL-12 & $\begin{array}{l}\text { Glomerular expression of IL-12 predominantly occurs in class IV and V lupus } \\
\text { nephritis, serum and urine IL-12 higher in lupus nephritis than nonrenal SLE }\end{array}$ \\
\hline $\begin{array}{l}\text { Fu et al., } 2008 \\
{[66]}\end{array}$ & $\begin{array}{l}\text { Peripheral blood leukocyte } \\
\text { chemokine transcriptional } \\
\text { levels }\end{array}$ & $\begin{array}{l}\text { Interferon-inducible chemokines in peripheral blood leucocytes higher in active } \\
\text { than inactive lupus nephritis and associated with SLE disease activity score }\end{array}$ \\
\hline $\begin{array}{l}\text { Morgan et al., } \\
2007 \text { [67] }\end{array}$ & Serum apoCIII & $\begin{array}{l}\text { Total apolipoprotein (apo) CIII levels significantly elevated in lupus nephritis than } \\
\text { nonrenal SLE and controls }\end{array}$ \\
\hline $\begin{array}{l}\text { Sabry et al., } \\
2007[68]\end{array}$ & Serum ICAM-1 & $\begin{array}{l}\text { Intracellular adhesion molecule (ICAM)-1 level significantly higher in lupus } \\
\text { nephritis than nonrenal SLE and correlates with disease activity score }\end{array}$ \\
\hline $\begin{array}{l}\text { Tseng et al., } \\
2007[69]\end{array}$ & $\begin{array}{l}\text { Antiendothelial cell } \\
\text { antibody }\end{array}$ & $\begin{array}{l}\text { Antiendothelial cell antibody titer higher in active lupus nephritis than nonrenal } \\
\text { SLE and correlates with disease activity score }\end{array}$ \\
\hline
\end{tabular}

TABLE 2: Urine biomarkers that correlate with lupus nephritis activity in cross-sectional studies.

\begin{tabular}{|c|c|c|}
\hline Authors, year & Biomarkers studied & Main findings \\
\hline $\begin{array}{l}\text { Kiani et al., } 2009 \\
{[13]}\end{array}$ & $\begin{array}{l}\text { Urine osteoprotegerin } \\
\text { (OPG) }\end{array}$ & $\begin{array}{l}\text { OPG strongly associated with renal activity descriptors of the SELENA SLEDAI; } \\
\text { medium/high levels of OPG predictive of a urine protein/creatinine ratio of } \geq 0.5\end{array}$ \\
\hline $\begin{array}{l}\text { Wang et al., } \\
2009[73]\end{array}$ & $\begin{array}{l}\text { FOXP3 mRNA expression } \\
\text { in urinary sediments }\end{array}$ & $\begin{array}{l}\text { FOXP3 mRNA expression significantly higher in active than inactive lupus } \\
\text { nephritis, and in proliferative than nonproliferative nephritis, FOXP3 mRNA level } \\
\text { correlated with proteinuria and histological activity index; persistent elevation } \\
\text { associated with poor treatment response }\end{array}$ \\
\hline $\begin{array}{l}\text { Dhaun et al., } \\
2009 \text { [74] }\end{array}$ & Urine endothelin-1 & $\begin{array}{l}\text { Fractional excretion of endothelin- } 1 \text { and urinary endothelin- } 1 / \text { creatinine ratio } \\
\text { higher in lupus nephritis than other chronic inflammatory renal diseases when } \\
\text { renal function is normal }\end{array}$ \\
\hline $\begin{array}{l}\text { En ghard et al., } \\
2009[75]\end{array}$ & $\begin{array}{l}\text { Urine CXCR3+CD } 4+\mathrm{T} \\
\text { cells }\end{array}$ & $\begin{array}{l}\text { Urinary CXCR } 3+C D 4+T \text { cells are enriched in lupus nephritis and correlated with } \\
\text { SLE disease activity; higher concentration of urinary CXCR3+CD } 4+T \text { cells is } \\
\text { found in active than inactive nephritis }\end{array}$ \\
\hline $\begin{array}{l}\text { Tucci et al., } 2008 \\
{[65]}\end{array}$ & Serum and urine IL-12 & $\begin{array}{l}\text { Glomerular expression of IL-12 predominantly occurs in class IV and V lupus } \\
\text { nephritis; serum and urine IL-12 higher in lupus nephritis than nonrenal SLE }\end{array}$ \\
\hline $\begin{array}{l}\text { Wu et al., } 2007 \\
{[76]}\end{array}$ & $\begin{array}{l}\text { Urine VCAM-1, P-selectin, } \\
\text { TNFR-1, and CXCL16 }\end{array}$ & $\begin{array}{l}\text { Urinary VCAM-1, P-selectin, TNFR-1, and CXCL16 elevated in lupus nephritis, } \\
\text { correlating with proteinuria and SLE disease activity scores; urinary VCAM-1 and } \\
\text { CXCL16 showed superior specificity and sensitivity in distinguishing subjects with } \\
\text { active renal disease from the other SLE patients. }\end{array}$ \\
\hline $\begin{array}{l}\text { Hammad et al., } \\
2006 \text { [77] }\end{array}$ & Urine TGF $\beta-1$ & $\begin{array}{l}\text { Urinary TGF } \beta \text {-1 level significantly higher in active than silent lupus nephritis, } \\
\text { correlated with anti-dsDNA and C3 levels }\end{array}$ \\
\hline $\begin{array}{l}\text { Chan et al., } 2004 \\
{[78]}\end{array}$ & $\begin{array}{l}\text { TGF } \beta \text { and MCP- } 1 \text { mRNA } \\
\text { expression in urine } \\
\text { sediments }\end{array}$ & $\begin{array}{l}\text { Urinary TGF } \beta \text { and MCP-1 mRNA expression correlated with histological activity } \\
\text { index on renal biopsy }\end{array}$ \\
\hline
\end{tabular}

Patients who achieved clinical remission had significant reduction in both antinucleosome and anti-dsDNA titers. The predictive values of rising antinucleosome and antidsDNA titers for renal flares were not evaluated and compared in this study, probably because of the relatively short period of observation (mean 37 weeks). Although it is shown that antinucleosome antibodies are useful in the monitoring of lupus nephritis, there performance for predicting renal flares and outcome does not appear to be superior to antidsDNA.
3.5.3. Anti- $\alpha$-Actinin Antibodies. Alpha-actinin-4 belongs to a family of actin-binding proteins that is expressed by podocytes and mesangial cells in renal tissues [93]. In murine studies, the pathogenicity of nephritogenic anti-dsDNA or antinucleosome antibodies is thought to be mediated by cross-reactivity with $\alpha$-actinin [94, 95]. A greater proportion of anti-dsDNA IgG-binding antibodies purified from patients with active lupus nephritis binds to $\alpha$-actinin than do those purified from sera of SLE patients without renal disease [96]. 
TABLE 3: Biomarkers that correlate with histological findings in lupus nephritis.

\begin{tabular}{|c|c|c|}
\hline Authors, year & Biomarkers studied & Main findings \\
\hline $\begin{array}{l}\text { Oates et al., } \\
2008 \text { [83] }\end{array}$ & $\begin{array}{l}\text { Serum nitrate and nitrite } \\
\text { levels }\end{array}$ & $\begin{array}{l}\text { Serum nitrate plus nitrite levels associated with SLE disease activity score; higher } \\
\text { nitrate/nitrite levels associated with histological proliferative renal lesions }\end{array}$ \\
\hline $\begin{array}{l}\text { Marks et al., } \\
2008[84]\end{array}$ & $\begin{array}{l}\text { Glomerular MCP-1 } \\
\text { expression }\end{array}$ & $\begin{array}{l}\text { Glomerular monocyte chemoattractant protein-1 (MCP-1) expression higher in } \\
\text { class III and class IV than other classes of lupus nephritis }\end{array}$ \\
\hline $\begin{array}{l}\text { Nakayamada et } \\
\text { al., } 2007[85]\end{array}$ & $\begin{array}{l}\beta 1 \text {-integrin }(\mathrm{CD} 29) \\
\text { expression on T cells }\end{array}$ & $\begin{array}{l}\text { CD29 expression on T cells upregulated in active SLE, especially in active diffuse } \\
\text { proliferative lupus nephritis }\end{array}$ \\
\hline $\begin{array}{l}\text { Avihingsanon et } \\
\text { al., } 2006 \text { [86] }\end{array}$ & $\begin{array}{l}\text { Chemokine and growth } \\
\text { factor mRNA levels in } \\
\text { urinary sediments }\end{array}$ & $\begin{array}{l}\text { Urine interferon-producing protein } 10 \text { (IP-10), CXCR3, TGF- } \beta \text {, and VEGF mRNA } \\
\text { levels associated with class IV lupus nephritis }\end{array}$ \\
\hline $\begin{array}{l}\text { do Nascimento } \\
\text { et al., } 2006[87]\end{array}$ & Antiribosomal P antibody & $\begin{array}{l}\text { Frequency of antiribosomal } \mathrm{P} \text { antibody higher in class } \mathrm{V} \text { than other classes of lupus } \\
\text { nephritis }\end{array}$ \\
\hline $\begin{array}{l}\text { Oates et al., } \\
2005[88]\end{array}$ & Urine glycoprotein panel & $\begin{array}{l}\text { An urinary glycoprotein panel may help to differentiate different histological classes } \\
\text { of lupus nephritis }\end{array}$ \\
\hline
\end{tabular}

TABLE 4: Biomarkers that correlate with prognosis in lupus nephritis.

\begin{tabular}{|c|c|c|}
\hline Authors, year & Biomarkers studied & Main findings \\
\hline $\begin{array}{l}\text { Izmirly et al., } \\
2009 \text { [89] }\end{array}$ & $\begin{array}{l}\text { mEPCR expression on } \\
\text { renal biopsy }\end{array}$ & $\begin{array}{l}\text { Membrane expression of endothelial protein C receptor (mEPCR) in the renal } \\
\text { microvasculature in lupus nephritis associated with poor therapeutic response }\end{array}$ \\
\hline $\begin{array}{l}\text { Avihingsanon et } \\
\text { al., } 2009[90]\end{array}$ & VEGF expression & $\begin{array}{l}\text { Intrarenal vascular endothelial growth factor (VEGF) mRNA expression predicted } \\
\text { the deterioration of renal function in lupus nephritis }\end{array}$ \\
\hline $\begin{array}{l}\text { Marks et al., } \\
2008[84]\end{array}$ & $\begin{array}{l}\text { Glomerular MCP-1 } \\
\text { expression }\end{array}$ & $\begin{array}{l}\text { Glomerular monocyte chemoattractant protein-1 (MCP-1) expression associated } \\
\text { with poor renal prognosis in pediatric lupus nephritis }\end{array}$ \\
\hline $\begin{array}{l}\text { Oates et al., } \\
2008[83]\end{array}$ & $\begin{array}{l}\text { Serum nitrate and nitrite } \\
\text { levels }\end{array}$ & $\begin{array}{l}\text { Higher serum nitrate plus nitrite levels associated with renal damage and treatment } \\
\text { failure in lupus nephritis }\end{array}$ \\
\hline $\begin{array}{l}\text { Martinez- } \\
\text { Lostao et al., } \\
2007[91]\end{array}$ & $\begin{array}{l}\text { STAT-1 expression on renal } \\
\text { biopsy }\end{array}$ & $\begin{array}{l}\text { Expression of STAT-1 in renal tissues associated with worse renal function and } \\
\text { outcome in class IV lupus nephritis }\end{array}$ \\
\hline $\begin{array}{l}\text { Avihingsanon et } \\
\text { al., } 2006 \text { [86] }\end{array}$ & $\begin{array}{l}\text { Chemokine and growth } \\
\text { factor mRNA levels in } \\
\text { urinary sediments }\end{array}$ & $\begin{array}{l}\text { Persistent elevation or increase of urine interferon-producing protein } 10 \text { (IP-10), } \\
\text { CXCR3, TGF- } \beta \text {, and VEGF mRNA levels associated with treatment failure in lupus } \\
\text { nephritis }\end{array}$ \\
\hline
\end{tabular}

Two cross-sectional studies have examined the association between anti- $\alpha$-actinin levels and disease activity in SLE patients [97, 98]. In one study [97], 21\% of patients with SLE had positive anti- $\alpha$-actinin antibodies and in these patients, renal involvement was significantly more common than in those without the anti- $\alpha$-actinin antibodies. In patients with lupus nephritis, anti- $\alpha$-actinin, but not anti-dsDNA, levels, correlated with the SLEDAI scores. In the other study [98], anti- $\alpha$-actinin antibodies were detected in $20 \%$ of SLE patients but were nonspecific for SLE because they were also positive in other disease controls. Among patients with SLE, anti- $\alpha$-actinin antibody levels were significantly higher in those with renal flares and correlated independently with anti-dsDNA titers.

A recent prospective study by Manson et al. [92] did not show any correlation between anti- $\alpha$-actinin and the anti-dsDNA or antinucleosome antibodies in a longitudinal cohort of patients with active lupus nephritis. At baseline, levels of anti- $\alpha$-actinin were not significantly higher in lupus nephritis patients than in controls. Anti- $\alpha$-actinin titers did not correlate with proteinuria, serum albumin, or remission status.
Although newer autoantibodies are available and useful for the monitoring of lupus nephritis activity, they are generally not more sensitive than conventional markers such as anti-dsDNA and complements in predicting renal flares. The usefulness of these autoantibodies in the monitoring of disease activity in subsets of SLE patients in whom conventional markers are negative has yet to be studied. The performance of a panel of conventional and novel autoantibodies in the diagnosis, monitoring, and prognostic stratification of lupus nephritis has to be evaluated in the future.

\section{Biomarkers Correlating with Lupus Renal Activity in Cross-Sectional Studies}

Literature search reveals quite a number of cross-sectional studies on the relationship between novel biomarkers and activity of lupus nephritis [13, 63-69, 73-78]. These are summarized in Table 1 (serum biomarkers) and Table 2 (urine biomarkers). Although some of these markers appear to be promising, a common problem is the lack of validation 
in a larger longitudinal cohort of patients with lupus nephritis. Moreover, results of individual biomarkers are not confirmed by independent groups of investigators. The specificity of these biomarkers for SLE and for lupus renal activity in particular, as well as their relationship with histological disease activity, has to be explored further.

\section{Biomarkers That Correlate with Histology or Prognosis of Lupus Nephritis}

Tables 3 and 4 summarize the biomarkers that have been associated with histological classes or renal function deterioration in lupus nephritis [83-91]. The quest continues for biomarkers that can differentiate different histological classes of lupus nephritis. Although some of these biomarkers are upregulated in the proliferative types of lupus nephritis, they cannot at this juncture replace the need for standard renal biopsy to delineate the histological features and the relative degree of activity and chronicity of the renal lesions. Further correlation studies between these biomarkers and the histologic activity and chronicity scores are necessary to evaluate their usefulness in prognostic stratification.

\section{Conclusions and Take-Home Messages}

Although a large number of novel biomarkers have been studied in lupus nephritis, none of them have been rigorously validated in large-scale longitudinal cohorts of patients with different ethnic background. It is unlikely at this juncture that a candidate biomarker stand-alone can replace conventional clinical parameters to monitor disease progress and detect early renal flares. Urine biomarkers appear to be more encouraging than serum biomarkers possibly because they are the direct products or consequences of kidney inflammation or injury. Future directions in SLE biomarker research should focus on a combination of novel markers with conventional clinical parameters to enhance the sensitivity and specificity for the prediction of renal flares and prognosis in lupus nephritis.

\section{References}

[1] C. C. Mok, S. S. K. Tang, C. H. To, and M. Petri, "Incidence and risk factors of thromboembolism in systemic lupus erythematosus: a comparison of three ethnic groups," Arthritis and Rheumatism, vol. 52, no. 9, pp. 2774-2782, 2005.

[2] C. C. Mok and S. S. K. Tang, "Incidence and predictors of renal disease in Chinese patients with systemic lupus erythematosus," American Journal of Medicine, vol. 117, no. 10, pp. 791-795, 2004.

[3] C. C. Mok, "Prognostic factors in lupus nephritis," Lupus, vol. 14, no. 1, pp. 39-44, 2005.

[4] M. A. Dooley, S. Hogan, C. Jennette, and R. Falk, "Cyclophosphamide therapy for lupus nephritis: poor renal survival in black Americans," Kidney International, vol. 51, no. 4, pp. 1188-1195, 1997.

[5] C. C. Mok, "Therapeutic options for resistant Lupus nephritis," Seminars in Arthritis and Rheumatism, vol. 36, no. 2, pp. 7181, 2006.
[6] C. C. Mok, "Update on emerging drug therapies for systemic lupus erythematosus," Expert Opinion on Emerging Drugs, vol. 15, pp. 53-70, 2010.

[7] B. H. Rovin, D. J. Birmingham, H. N. Nagaraja, C. Y. Yu, and L. A. Hebert, "Biomarker discovery in human SLE nephritis," Bulletin of the NYU Hospital for Joint Diseases, vol. 65, no. 3, pp. 187-193, 2007.

[8] G. H. Tesch, S. Maifert, A. Schwarting, B. J. Rollins, and V. R. Kelley, "Monocyte chemoattractant protein 1-dependent leukocytic infiltrates are responsible for autoimmune disease in MRL-Fas(lpr) mice," Journal of Experimental Medicine, vol. 190, no. 12, pp. 1813-1824, 1999.

[9] H. Hasegawa, M. Kohno, Miho Sasaki, et al., "Antagonist of monocyte chemoattractant protein 1 ameliorates the initiation and progression of lupus nephritis and renal vasculitis in MRL/lpr mice," Arthritis and Rheumatism, vol. 48, no. 9, pp. 2555-2566, 2003.

[10] T. Wada, C. Segawa, S. B. Su, et al., "Monitoring urinary levels of monocyte chemotactic and activating factor reflects disease activity of lupus nephritis," Kidney International, vol. 49, no. 3, pp. 761-767, 1996.

[11] B. H. Rovin, N. Doe, and L. C. Tan, "Monocyte chemoattractant protein-1 levels in patients with glomerular disease," American Journal of Kidney Diseases, vol. 27, no. 5, pp. 640646, 1996.

[12] M. Noris, S. Bernasconi, F. Casiraghi, et al., "Monocyte chemoattractant protein-1 is excreted in excessive amounts in the urine of patients with lupus nephritis," Laboratory Investigation, vol. 73, no. 6, pp. 804-809, 1995.

[13] A. N. Kiani, K. Johnson, C. Chen, et al., "Urine osteoprotegerin and monocyte chemoattractant protein-1 in lupus nephritis," Journal of Rheumatology, vol. 36, no. 10, pp. 22242230, 2009.

[14] B. H. Rovin, H. Song, D. J. Birmingham, L. A. Hebert, C. Y. $\mathrm{Yu}$, and H. N. Nagaraja, "Urine chemokines as biomarkers of human systemic lupus erythematosus activity," Journal of the American Society of Nephrology, vol. 16, no. 2, pp. 467-473, 2005.

[15] M. Tucci, E. V. Barnes, E. S. Sobel, et al., "Strong association of a functional polymorphism in the monocyte chemoattractant protein 1 promoter gene with lupus nephritis," Arthritis and Rheumatism, vol. 50, no. 6, pp. 1842-1849, 2004.

[16] S. Tian, Y. Wang, J. Jia, et al., "Urinary levels of RANTES and $\mathrm{M}-\mathrm{CSF}$ are predictors of lupus nephritis flare," Inflammation Research, vol. 56, no. 7, pp. 304-310, 2007.

[17] R. W. Y. Chan, F. M. M. Lai, E. K. M. Li, et al., "The effect of immunosuppressive therapy on the messenger RNA expression of target genes in the urinary sediment of patients with active lupus nephritis," Nephrology Dialysis Transplantation, vol. 21, no. 6, pp. 1534-1540, 2006.

[18] N. Schwartz, J. S. Michaelson, and C. Putterman, "Lipocalin-2, TWEAK, and other cytokines as urinary biomarkers for lupus nephritis," Annals of the New York Academy of Sciences, vol. 1109, pp. 265-274, 2007.

[19] J. Mishra, M. A. Qing, A. Prada, et al., "Identification of neutrophil gelatinase-associated lipocalin as a novel early urinary biomarker for ischemic renal injury," Journal of the American Society of Nephrology, vol. 14, no. 10, pp. 2534-2543, 2003.

[20] J. Mishra, K. Mori, Q. Ma, C. Kelly, J. Barasch, and P. Devarajan, "Neutrophil gelatinase-associated lipocalin: a novel early urinary biomarker for cisplatin nephrotoxicity," American Journal of Nephrology, vol. 24, no. 3, pp. 307-315, 2004. 
[21] H. Trachtman, E. Christen, A. Cnaan, et al., "Urinary neutrophil gelatinase-associated lipocalcin in D+HUS: a novel marker of renal injury," Pediatric Nephrology, vol. 21, no. 7, pp. 989-994, 2006.

[22] T. Rubinstein, M. Pitashny, and C. Putterman, "The novel role of neutrophil gelatinase-B associated lipocalin (NGAL)/Lipocalin-2 as a biomarker for lupus nephritis," Autoimmunity Reviews, vol. 7, no. 3, pp. 229-234, 2008.

[23] J. Mishra, C. Dent, R. Tarabishi, et al., "Neutrophil gelatinaseassociated lipocalin (NGAL) as a biomarker for acute renal injury after cardiac surgery," The Lancet, vol. 365, no. 9466, pp. 1231-1238, 2005.

[24] D. Bolignano, A. Lacquaniti, G. Coppolino, S. Campo, A. Arena, and M. Buemi, "Neutrophil gelatinase-associated lipocalin reflects the severity of renal impairment in subjects affected by chronic kidney disease," Kidney and Blood Pressure Research, vol. 31, no. 4, pp. 255-258, 2008.

[25] D. Bolignano, V. Donato, G. Coppolino, et al., "Neutrophil gelatinase-associated lipocalin (NGAL) as a marker of kidney damage," American Journal of Kidney Diseases, vol. 52, no. 3, pp. 595-605, 2008.

[26] X. Qing, J. Zavadil, M. B. Crosby, et al., "Nephritogenic antiDNA antibodies regulate gene expression in MRL/lpr mouse glomerular mesangial cells," Arthritis and Rheumatism, vol. 54, no. 7, pp. 2198-2210, 2006.

[27] H. I. Brunner, M. Mueller, C. Rutherford, et al., "Urinary neutrophil gelatinase-associated lipocalin as a biomarker of nephritis in childhood-onset systemic lupus erythematosus," Arthritis and Rheumatism, vol. 54, no. 8, pp. 2577-2584, 2006.

[28] M. Pitashny, N. Schwartz, X. Qing, et al., "Urinary lipocalin2 is associated with renal disease activity in human lupus nephritis," Arthritis and Rheumatism, vol. 56, no. 6, pp. 18941903, 2007.

[29] M. Suzuki, K. M. Wiers, M. S. Klein-Gitelman, et al., "Neutrophil gelatinase-associated lipocalin as a biomarker of disease activity in pediatric lupus nephritis," Pediatric Nephrology, vol. 23, no. 3, pp. 403-412, 2008.

[30] C. H. Hinze, M. Suzuki, M. Klein-Gitelman, et al., "Neutrophil gelatinase-associated lipocalin is a predictor of the course of global and renal childhood-onset systemic lupus erythematosus disease activity," Arthritis and Rheumatism, vol. 60, no. 9, pp. 2772-2781, 2009.

[31] T. Rubinstein, M. Pitashny, and B. Levine, "Urinary neutrophil gelatinase-associated lipocalin as a novel biomarker for disease activity in lupus nephritis," Rheumatology. In press.

[32] A. Ortiz, A. B. Sanz, B. M. García, et al., "Considering TWEAK as a target for therapy in renal and vascular injury," Cytokine and Growth Factor Reviews, vol. 20, no. 3, pp. 251-258, 2009.

[33] J. A. Winkles, "The TWEAK-Fn14 cytokine-receptor axis: discovery, biology and therapeutic targeting," Nature Reviews Drug Discovery, vol. 7, no. 5, pp. 411-425, 2008.

[34] S. Campbell, C. L. Putterman, H. X. Gao, et al., "Proinflammatory effects of Tweak/Fn14 interactions in glomerular mesangial cells," Journal of Immunology, vol. 176, no. 3, pp. 1889-1898, 2006.

[35] H. X. Gao, S. R. Campbell, L. C. Burkly, et al., "TNF-like weak inducer of apoptosis (TWEAK) induces inflammatory and proliferative effects in human kidney cells," Cytokine, vol. 46, no. 1, pp. 24-35, 2009.

[36] U. S. Gaipl, R. E. Voll, A. Sheriff, S. Franz, J. R. Kalden, and M. Herrmann, "Impaired clearance of dying cells in systemic lupus erythematosus," Autoimmunity Reviews, vol. 4, no. 4, pp. 189-194, 2005.
[37] M. J. Kaplan, E. E. Lewis, E. A. Shelden, et al., "The apoptotic ligands TRAIL, TWEAK, and fas ligand mediate monocyte death induced by autologous lupus T cells," Journal of Immunology, vol. 169, no. 10, pp. 6020-6029, 2002.

[38] N. Schwartz, L. Su, L. C. Burkly, et al., "Urinary TWEAK and the activity of lupus nephritis," Journal of Autoimmunity, vol. 27, no. 4, pp. 242-250, 2006.

[39] N. Schwartz, T. Rubinstein, L. C. Burkly, et al., "Urinary TWEAK as a biomarker of lupus nephritis: a multicenter cohort study," Arthritis Research \& Therapy, vol. 11, no. 5, p. R143, 2009.

[40] M. Suzuki, G. F. Ross, K. Wiers, et al., "Identification of a urinary proteomic signature for lupus nephritis in children," Pediatric Nephrology, vol. 22, no. 12, pp. 2047-2057, 2007.

[41] K. Mosley, F. W. Tam, R. J. Edwards, J. Crozier, C. D. Pusey, and L. Lightstone, "Urinary proteomic profiles distinguish between active and inactive lupus nephritis," Rheumatology, vol. 45, no. 12, pp. 1497-1504, 2006.

[42] M. Suzuki, K. Wiers, E. B. Brooks, et al., "Initial validation of a novel protein biomarker panel for active pediatric lupus nephritis," Pediatric Research, vol. 65, no. 5, pp. 530-536, 2009.

[43] J. Malyszko and M. Mysliwiec, "Hepcidin in anemia and inflammation in chronic kidney disease," Kidney and Blood Pressure Research, vol. 30, no. 1, pp. 15-30, 2007.

[44] E. Nemeth, E. V. Valore, M. Territo, G. Schiller, A. Lichtenstein, and T. Ganz, "Hepcidin, a putative mediator of anemia of inflammation, is a type II acute-phase protein," Blood, vol. 101, no. 7, pp. 2461-2463, 2003.

[45] P. Lee, H. Peng, T. Gelbart, L. Wang, and E. Beutler, "Regulation of hepcidin transcription by interleukin-1 and interleukin-6," Proceedings of the National Academy of Sciences of the United States of America, vol. 102, no. 6, pp. 1906-1910, 2005.

[46] X. Zhang, M. Jin, H. Wu, et al., "Biomarkers of lupus nephritis determined by serial urine proteomics," Kidney International, vol. 74, no. 6, pp. 799-807, 2008.

[47] A. Tsirogianni, E. Pipi, and K. Soufleros, "Relevance of antiC1q autoantibodies to lupus nephritis," Annals of the New York Academy of Sciences, vol. 1173, pp. 243-251, 2009.

[48] M. Trendelenburg, "Antibodies against C1q in patients with systemic lupus erythematosus," Springer Seminars in Immunopathology, vol. 27, no. 3, pp. 276-285, 2005.

[49] M. A. Seelen, L. A. Trouw, and M. R. Daha, "Diagnostic and prognostic significance of anti-Clq antibodies in systemic lupus erythematosus," Current Opinion in Nephrology and Hypertension, vol. 12, no. 6, pp. 619-624, 2003.

[50] A. J. Jesus, C. A. Silva, M. Carneiro-Sampaio, et al., "Anti-C1q antibodies in juvenile-onset systemic lupus erythematosus," Annals of the New York Academy of Sciences, vol. 1173, pp. 235238, 2009.

[51] C. E. H. Siegert, M. R. Daha, C. M. E. S. Tseng, I. E. M. Coremans, L. A. van Es, and F. C. Breedveld, "Predictive value of IgG autoantibodies against C1q for nephritis in systemic lupus erythematosus," Annals of the Rheumatic Diseases, vol. 52, no. 12, pp. 851-856, 1993.

[52] C. G. Moura, I. Lima, L. Barbosa, et al., "Anti-C1q antibodies: association with nephritis and disease activity in systemic lupus erythematosus," Journal of Clinical Laboratory Analysis, vol. 23, no. 1, pp. 19-23, 2009.

[53] Q. Y. Fang, F. Yu, Y. Tan, et al., "Anti-C1q antibodies and IgG subclass distribution in sera from Chinese patients with lupus nephritis," Nephrology Dialysis Transplantation, vol. 24, no. 1, pp. 172-178, 2009. 
[54] R. A. Sinico, A. Radice, M. Ikehata, et al., "Anti-C1q autoantibodies in lupus nephritis: prevalence and clinical significance," Annals of the New York Academy of Sciences, vol. 1050, pp. 193200, 2005.

[55] F. Q. Wu, Q. Zhao, X. D. Cui, and W. Zhang, "C1q and anti$\mathrm{Clq}$ antibody levels are correlated with disease severity in Chinese pediatric systemic lupus erythematosus," Rheumatology International. In press.

[56] M. Mosca, D. Chimenti, F. Pratesi, et al., "Prevalence and clinico-serological correlations of anti- $\alpha$-enolase, anti-C1q, and anti-dsDNA antibodies in patients with systemic lupus erythematosus," Journal of Rheumatology, vol. 33, no. 4, pp. 695-697, 2006.

[57] P. Horák, Z. Hermanová, J. Zadrazil, et al., "C1q complement component and antibodies reflect SLE activity and kidney involvement," Clinical Rheumatology, vol. 25, no. 4, pp. 532536, 2006.

[58] G. Moroni, M. Trendelenburg, N. Del Papa, et al., "Anti$\mathrm{Clq}$ antibodies may help in diagnosing a renal flare in lupus nephritis," American Journal of Kidney Diseases, vol. 37, no. 3, pp. 490-498, 2001.

[59] M. Trendelenburg, M. Lopez-Trascasa, E. Potlukova, et al., "High prevalence of anti-C1q antibodies in biopsy-proven active lupus nephritis," Nephrology Dialysis Transplantation, vol. 21, no. 11, pp. 3115-3121, 2006.

[60] R. A. Sinico, L. Rimoldi, A. Radice, L. Bianchi, B. Gallelli, and G. Moroni, "Anti-C1q autoantibodies in lupus nephritis," Annals of the New York Academy of Sciences, vol. 1173, pp. 4751, 2009.

[61] O. C. Meyer, P. Nicaise-Roland, N. Cadoudal, et al., "Anti$\mathrm{C} 1 \mathrm{q}$ antibodies antedate patent active glomerulonephritis in patients with systemic lupus erythematosus," Arthritis Research and Therapy, vol. 11, no. 3, article R87, 2009.

[62] G. Moroni, A. Radice, G. Giammarresi, et al., "Are laboratory tests useful for monitoring the activity of lupus nephritis? A 6-year prospective study in a cohort of 228 patients with lupus nephritis," Annals of the Rheumatic Diseases, vol. 68, no. 2, pp. 234-237, 2009.

[63] A. D. C. Hoftman, L. Q. Tai, S. Tze, D. Seligson, R. A. Gatti, and D. K. McCurdy, "MAGE-B2 autoantibody: a new biomarker for pediatric systemic lupus erythematosus," Journal of Rheumatology, vol. 35, no. 12, pp. 2430-2438, 2008.

[64] Y. Tan, F. Yu, H. Yang, M. Chen, Qiying Fang, and M. H. Zhao, "Autoantibodies against monomeric C-reactive protein in sera from patients with lupus nephritis are associated with disease activity and renal tubulointerstitial lesions," Human Immunology, vol. 69, no. 12, pp. 840-844, 2008.

[65] M. Tucci, L. Lombardi, H. B. Richards, F. Dammacco, and F. Silvestris, "Overexpression of interleukin-12 and T helper 1 predominance in lupus nephritis," Clinical and Experimental Immunology, vol. 154, no. 2, pp. 247-254, 2008.

[66] Q. Fu, X. Chen, H. Cui, et al., "Association of elevated transcript levels of interferon-inducible chemokines with disease activity and organ damage in systemic lupus erythematosus patients," Arthritis Research and Therapy, vol. 10, no. 5, article R112, 2008.

[67] P. E. Morgan, A. D. Sturgess, A. Hennessy, and M. J. Davies, "Serum protein oxidation and apolipoprotein CIII levels in people with systemic lupus erythematosus with and without nephritis," Free Radical Research, vol. 41, no. 12, pp. 13011312, 2007.

[68] A. Sabry, H. Sheashaa, A. El-Husseini, K. El-Dahshan, M. Abdel-Rahim, and S. R. Elbasyouni, "Intercellular adhesion molecules in systemic lupus erythematosus patients with lupus nephritis," Clinical Rheumatology, vol. 26, no. 11, pp. 1819-1823, 2007.

[69] J. C. Tseng, L. Y. Lu, R. J. Hu, et al., "Elevated serum antiendothelial cell autoantibodies titer is associated with lupus nephritis in patients with systemic lupus erythematosus," Journal of Microbiology, Immunology and Infection, vol. 40, no. 1, pp. 50-55, 2007.

[70] A. Bruns, S. Bläss, G. Hausdorf, G. R. Burmester, and F. Hiepe, "Nucleosomes are major T and B cell autoantigens in systemic Lupus erythematosus," Arthritis and Rheumatism, vol. 43, no. 10, pp. 2307-2315, 2000.

[71] S. Koutouzov, A. L. Jeronimo, H. Campos, and Z. Amoura, "Nucleosomes in the pathogenesis of systemic lupus erythematosus," Rheumatic Disease Clinics of North America, vol. 30, no. 3, pp. 529-558, 2004.

[72] M. Kalaaji, K. A. Fenton, E. S. Mortensen, et al., "Glomerular apoptotic nucleosomes are central target structures for nephritogenic antibodies in human SLE nephritis," Kidney International, vol. 71, no. 7, pp. 664-672, 2007.

[73] G. Wang, F. M.-M. Lai, L.-S. Tam, et al., "Urinary FOXP3 mRNA in patients with lupus nephritis-relation with disease activity and treatment response," Rheumatology, vol. 48, no. 7, pp. 755-760, 2009.

[74] N. Dhaun, P. Lilitkarntakul, I. M. MacIntyre, et al., "Urinary endothelin-1 in chronic kidney disease and as a marker of disease activity in lupus nephritis," American Journal of Physiology, vol. 296, no. 6, pp. F1477-F1483, 2009.

[75] P. Enghard, J. Y. Humrich, B. Rudolph, et al., "CXCR3+CD4+ $\mathrm{T}$ cells are enriched in inflamed kidneys and urine and provide a new biomarker for acute nephritis flares in systemic lupus erythematosus patients," Arthritis and Rheumatism, vol. 60, no. 1, pp. 199-206, 2009.

[76] T. Wu, C. Xie, H. W. Wang, et al., "Elevated urinary VCAM1, P-selectin, soluble TNF receptor-1, and CXC chemokine ligand 16 in multiple murine lupus strains and human lupus nephritis," Journal of Immunology, vol. 179, no. 10, pp. 71667175, 2007.

[77] A. M. Hammad, H. M. Youssef, and M. M. El-Arman, "Transforming growth factor beta 1 in children with systemic lupus erythematosus: a possible relation with clinical presentation of lupus nephritis," Lupus, vol. 15, no. 9, pp. 608-612, 2006.

[78] R. W. Y. Chan, F. M. M. Lai, E. K. M. Li, et al., "Expression of chemokine and fibrosing factor messenger RNA in the urinary sediment of patients with lupus nephritis," Arthritis and Rheumatism, vol. 50, no. 9, pp. 2882-2890, 2004.

[79] J. A. Gómez-Puerta, R. W. Burlingame, and R. Cervera, "Antichromatin (anti-nucleosome) antibodies: diagnostic and clinical value," Autoimmunity Reviews, vol. 7, no. 8, pp. 606-611, 2008.

[80] R. Cervera, O. Viñas, M. Ramos-Casals, et al., "Anti-chromatin antibodies in systemic lupus erythematosus: a useful marker for lupus nephropathy," Annals of the Rheumatic Diseases, vol. 62, no. 5, pp. 431-434, 2003.

[81] Z. Amoura, S. Koutouzov, H. Chabre, et al., "Presence of antinucleosome autoantibodies in a restricted set of connective tissue diseases: antinucleosome antibodies of the IgG3 subclass are markers of renal pathogenicity in systemic lupus erythematosus," Arthritis and Rheumatism, vol. 43, no. 1, pp. 76-84, 2000.

[82] C. Grootscholten, J. W. C. Dieker, F. D. McGrath, et al., "A prospective study of anti-chromatin and antiC1q autoantibodies in patients with proliferative lupus 
nephritis treated with cyclophosphamide pulses or azathioprine/methylprednisolone," Annals of the Rheumatic Diseases, vol. 66, no. 5, pp. 693-696, 2007.

[83] J. C. Oates, S. R. Shaftman, S. E. Self, and G. S. Gilkeson, "Association of serum nitrate and nitrite levels with longitudinal assessments of disease activity and damage in systemic lupus erythematosus and lupus nephritis," Arthritis and Rheumatism, vol. 58, no. 1, pp. 263-272, 2008.

[84] S. D. Marks, S. J. Williams, K. Tullus, and N. J. Sebire, "Glomerular expression of monocyte chemoattractant protein-1 is predictive of poor renal prognosis in paediatric lupus nephritis," Nephrology Dialysis Transplantation, vol. 23, no. 11, pp. 3521-3526, 2008.

[85] S. Nakayamada, K. Saito, K. Nakano, and Y. Tanaka, "Activation signal transduction by $\beta 1$ integrin in $\mathrm{T}$ cells from patients with systemic lupus erythematosus," Arthritis and Rheumatism, vol. 56, no. 5, pp. 1559-1568, 2007.

[86] Y. Avihingsanon, P. Phumesin, T. Benjachat, et al., "Measurement of urinary chemokine and growth factor messenger RNAs: a noninvasive monitoring in lupus nephritis," Kidney International, vol. 69, no. 4, pp. 747-753, 2006.

[87] A. P. do Nascimento, V. D. S. T. Viana, L. D. A. Testagrossa, et al., "Antibodies to ribosomal P proteins: a potential serologic marker for lupus membranous glomerulonephritis," Arthritis and Rheumatism, vol. 54, no. 5, pp. 1568-1572, 2006.

[88] J. C. Oates, S. Varghese, A. M. Bland, et al., "Prediction of urinary protein markers in lupus nephritis," Kidney International, vol. 68 , no. 6 , pp. 2588-2592, 2005.

[89] P. M. Izmirly, L. Barisoni, J. P. Buyon, et al., "Expression of endothelial protein $\mathrm{C}$ receptor in cortical peritubular capillaries associates with a poor clinical response in lupus nephritis," Rheumatology, vol. 48, no. 5, pp. 513-519, 2009.

[90] Y. Avihingsanon, T. Benjachat, A. Tassanarong, P. Sodsai, V. Kittikovit, and N. Hirankarn, "Decreased renal expression of vascular endothelial growth factor in lupus nephritis is associated with worse prognosis," Kidney International, vol. 75, no. 12, pp. 1340-1348, 2009.

[91] L. Martinez-Lostao, J. Ordi-Ros, E. Balada, et al., "Activation of the signal transducer and activator of transcription-1 in diffuse proliferative lupus nephritis," Lupus, vol. 16, no. 7, pp. 483-488, 2007.

[92] J. J. Manson, A. Ma, P. Rogers, et al., "Relationship between anti-dsDNA, anti-nucleosome and anti-alpha-actinin antibodies and markers of renal disease in patients with lupus nephritis: a prospective longitudinal study," Arthritis Research \& Therapy, vol. 11, no. 5, p. R154, 2009.

[93] Y. Renaudineau, B. Deocharan, S. Jousse, E. Renaudineau, C. Putterman, and P. Youinou, "Anti-alpha-actinin antibodies: a new marker of lupus nephritis," Autoimmunity Reviews, vol. 6, no. 7, pp. 464-468, 2007.

[94] B. Deocharan, X. Qing, J. Lichauco, and C. Putterman, “ $\alpha$ actinin is a cross-reactive renal target for pathogenic anti-DNA aptibodies," Journal of Immunology, vol. 168, no. 6, pp. 30723078, 2002.

[95] Z. Zhao, E. Weinstein, M. Tuzova, et al., "Cross-reactivity of human lupus anti-DNA antibodies with $\alpha$-actinin and nephritogenic potential," Arthritis and Rheumatism, vol. 52, no. 2, pp. 522-530, 2005.

[96] L. J. Mason, C. T. Ravirajan, A. Rahman, C. Putterman, and D. A. Isenberg, "Is $\alpha$-actinin a target for pathogenic anti-DNA antibodies in lupus nephritis?" Arthritis and Rheumatism, vol. 50, no. 3, pp. 866-870, 2004.

[97] Y. Renaudineau, S. Croquefer, S. Jousse, et al., "Association of $\alpha$-actinin-binding anti-double-stranded DNA antibodies with lupus nephritis," Arthritis and Rheumatism, vol. 54, no. 8, pp. 2523-2532, 2006.

[98] A. Becker-Merok, M. Kalaaji, K. Haugbro, et al., " $\alpha$-actininbinding antibodies in relation to systemic lupus erythematosus and lupus nephritis," Arthritis Research and Therapy, vol. 8, no. 6, article R162, 2006. 


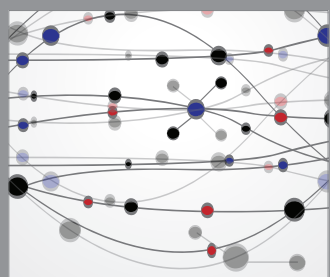

The Scientific World Journal
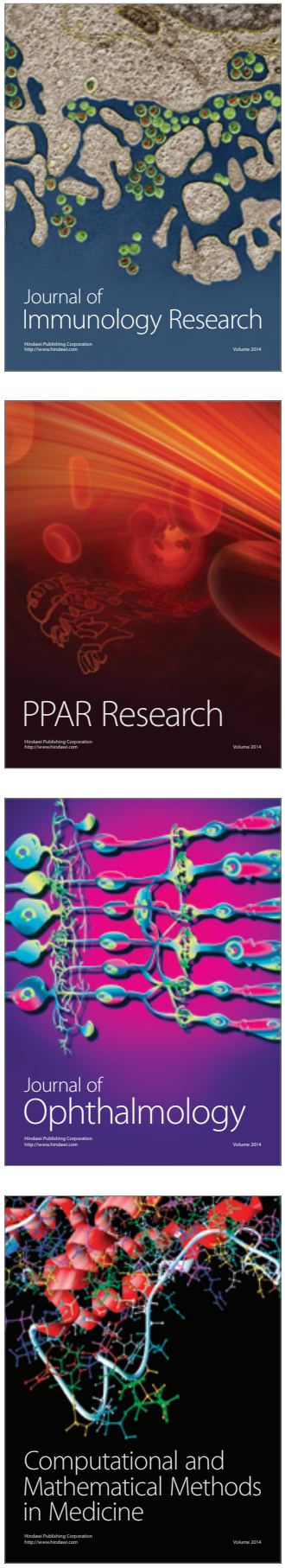

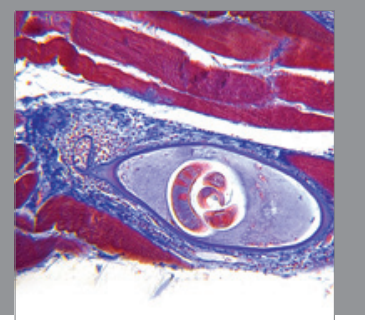

Gastroenterology

Research and Practice
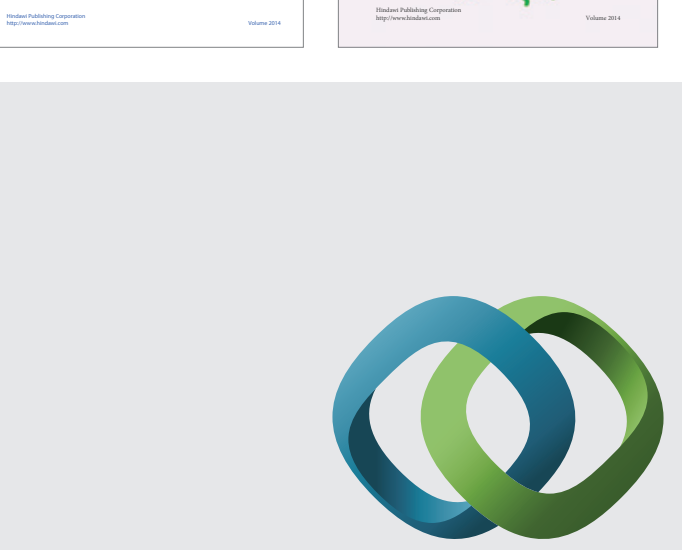

\section{Hindawi}

Submit your manuscripts at

http://www.hindawi.com
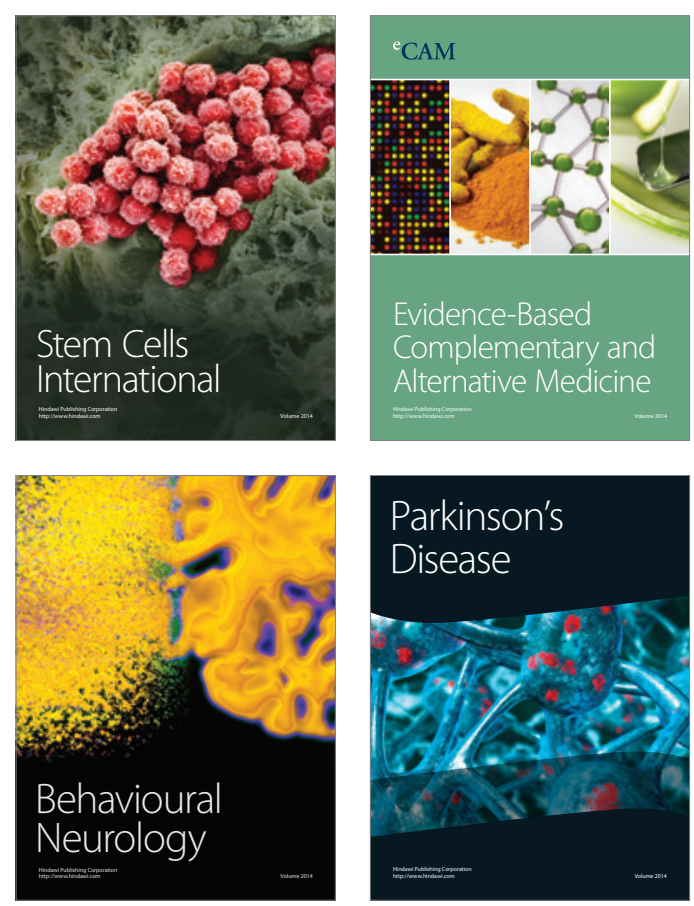

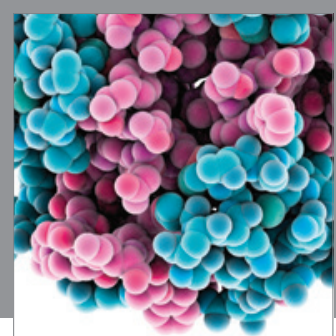

Journal of
Diabetes Research

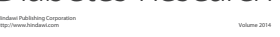

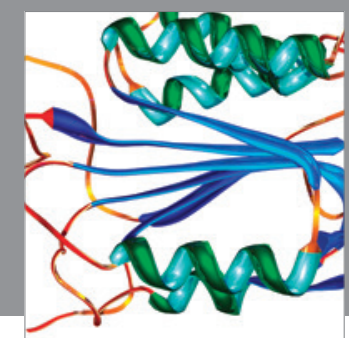

Disease Markers
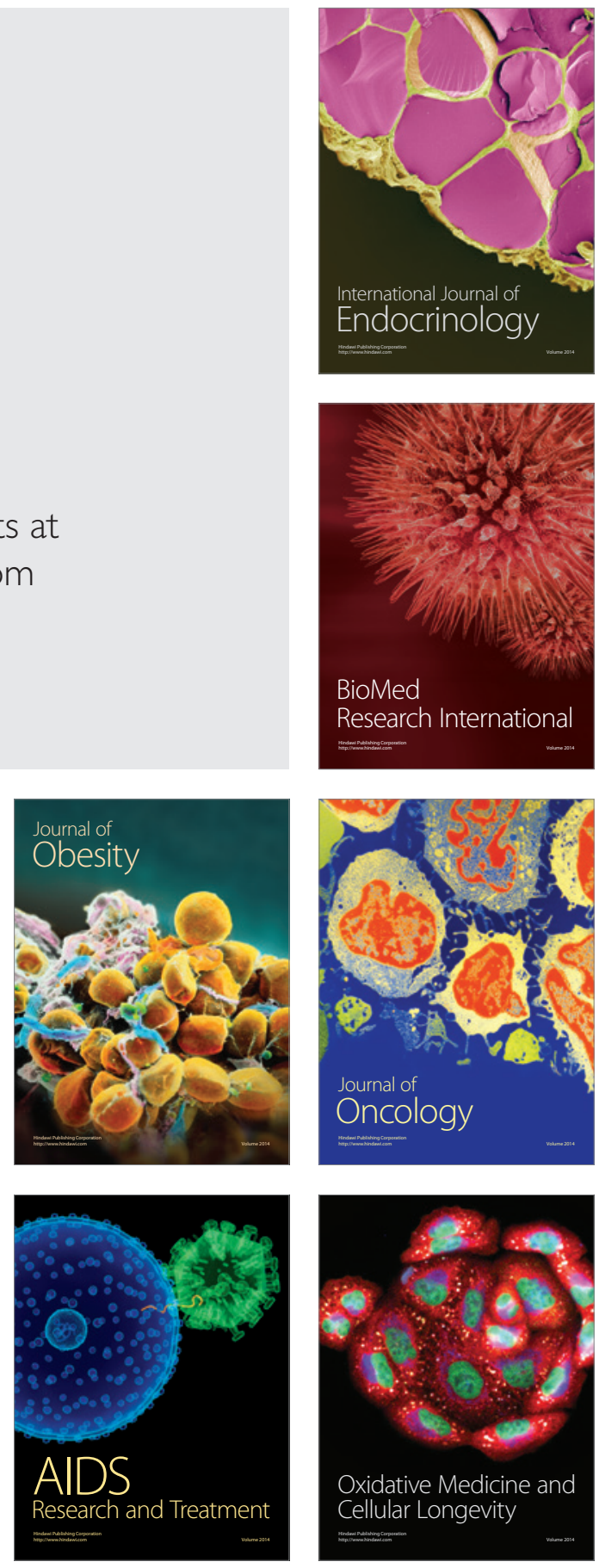